\title{
CZU:635.743:631.527.5 https://doi.org/10.53040/gppb7.2021.54 \\ MANIFESTAREA HETEROZISULUI LA HIBRIZI F1 DE Salvia sclarea L.
}

\author{
Cotelea Ludmila, Gonceariuc Maria, Butnaraş Violeta, Botnarenco P. \\ Institutul de Genetică, Fiziologie și Protecție a Plantelor, Chișinău, Republica Moldova \\ e-mail: ludmila.cotelea@igfpp.md
}

\begin{abstract}
22 hybrids $\mathrm{F}_{1}$ of Salvia sclarea $\mathrm{L}$., were evaluated, which show heterosis in a series of quantitative characters, which directly influence productivity, at the same time being a valuable breeding material for the elaboration of few varieties of hybrid origin. They showed a remarkable effect of heterosis on the number of branches of the inflorescence a hybrid in steps: $+55.8 \%$ in relation to the maternal form and $+61.4 \%$ in relation to the paternal form. The essential oil content is high $(0.877-1.836 \%)$; the highest effect of heterosis being recorded by a stepped hybrid: $+25.0 \%$ in relation to the maternal form, $+87.9 \%$ in relation to the paternal form.
\end{abstract}

Key words: Salvia sclarea L., hybrid, quantitative characters, essential oil, heterosis.

\section{Introducere}

Denumirea de heterozis se datorează lui G.H. Shull, care a utilizat pentru prima data acest termen in anul 1914 [6]. Heterozisul este utilizat în ameliorarea Salviei sclarea L. - specie aromatică şi medicinală valoroasă, datorită uleiului esenţial pe care îl conţine în inflorescenţe şi este foarte apreciat în industria parfumeriei, medicină, industria de fabricare a vinurilor de tip muscat, etc [4].

În rezultatul cercetărilor efectuate au fost creaţi hibrizi de diferite tipuri de Salvia sclarea, ce manifestă heterozis la caracterele cantitative cu impact asupra recoltei de materie primă şi producţiei de ulei esenţial $[1,2,4]$. În această lucrare, sunt prezentate rezultatele recent obţinute în crearea genotipurilor hibride perspective şi evaluarea valorii heterozisului la caracterele cantitative, care influenţează direct productivitatea şi calitatea.

\section{Materiale și metode}

Materialul biologic utilizat este reprezentat de 22 hibrizi $F_{1}$ simpli, tripli, dubli, în trepte și complecşi de Salvia sclarea, precum şi formele parentale ale acestora - linii consangvinizate de provenienţă genetică şi geografică diferită și hibrizi de diferite tipuri.

Pe parcursul perioadei de vegetaţie au fost efectuate evaluări fenologice, cercetări biometrice, aprecieri vizuale. Au fost studiaţi indicii caracterelor morfologice ce influenţează recolta de materie primă și producția de ulei esențial: talia plantei, lungimea inflorescenţei, numărul de ramificaţii de gradul întâi şi al doilea ale inflorescenței [3]. Conţinutul de ulei esențial a fost determinat prin hidrodistilare în aparate Ginsberg, recalculat ulterior la substanţă uscată.

Interpretatrea statistică a datelor experimentale obţinute s-a făcut conform metodelor în vigoare. Efectul heterozis a fost calculat în procente în raport cu ambele forme parentale ale fiecărui hibrid la următoarele caractere cantitative: talia plantei, lungimea inflorescenţei, numărul de ramificaţii ale inflorescenţei de ordinul I şi II, conţinutul de ulei esenţial [5].

\section{Rezultate şi discuţii}

Obiectivele principale în ameliorarea speciei Salvia sclarea, sunt crearea de noi soiuri, hibrizi, cu producţie înaltă de materie primă, conţinut ridicat de ulei esenţial. În acest scop au fost creaţi hibrizi $\mathrm{F}_{1}$, utilizând diferite tipuri de hibridări - simple, triliniare, duble, în trepte și complexe. Evaluarea hibrizilor creaţi a demonstrat, că aceştia sunt valoroşi printr-un şir de caractere, care asigură o productivitate sporită de materie primă și conţinut ridicat de ulei esenţial. La majoritatea din aceste caractere, hibrizii $\mathrm{F}_{1}$ manifestă heterozis. Astfel, la caracterul „talia plantei”, 13 hibrizi manifestă heterozis în raport cu ambele forme parentale și acest indice variază de la +0.2 până la $+25.8 \%$ la diferiţi hibrizi (figura 1 . nr. $1,2,3,4$, $5,9,11,12,13,14,15,20,21)$. Cinci din hibrizii evaluaţi nu manifestă heterozis, iar combinația hibridă 
simplă (AP 113-11 S 3 x NC 19-11 S3) $\mathrm{F}_{1}$ înregistrează heterozis nesemnificativ în raport cu forma maternă (fig. 1. nr. 8).

Cel mai înalt efect al heterozisului, în raport cu ambele forme parentale a fost înregistrat de trei hibrizi simpli (NC 19-11 $\mathrm{S}_{3}$ x AP 113-11 $\left.\mathrm{S}_{3}\right) \mathrm{F}_{1}-(+11,0-+21,9 \%)$, (NC 61-11 $\mathrm{S}_{3}$ x AP 34-11 $\left.\mathrm{S}_{3}\right) \mathrm{F}_{1}-$ $(+13,6-+25,8 \%)$ şi (AP 10-11 $\mathrm{S}_{3} \times$ AP $\left.114-11 \mathrm{~S}_{3}\right) \mathrm{F}_{1},-(+14,2-+25,9 \%)$, iar talia plantelor la aceste combinații hibride este de peste $132 \mathrm{~cm}$ (fig. 1. nr. 12,13,3).

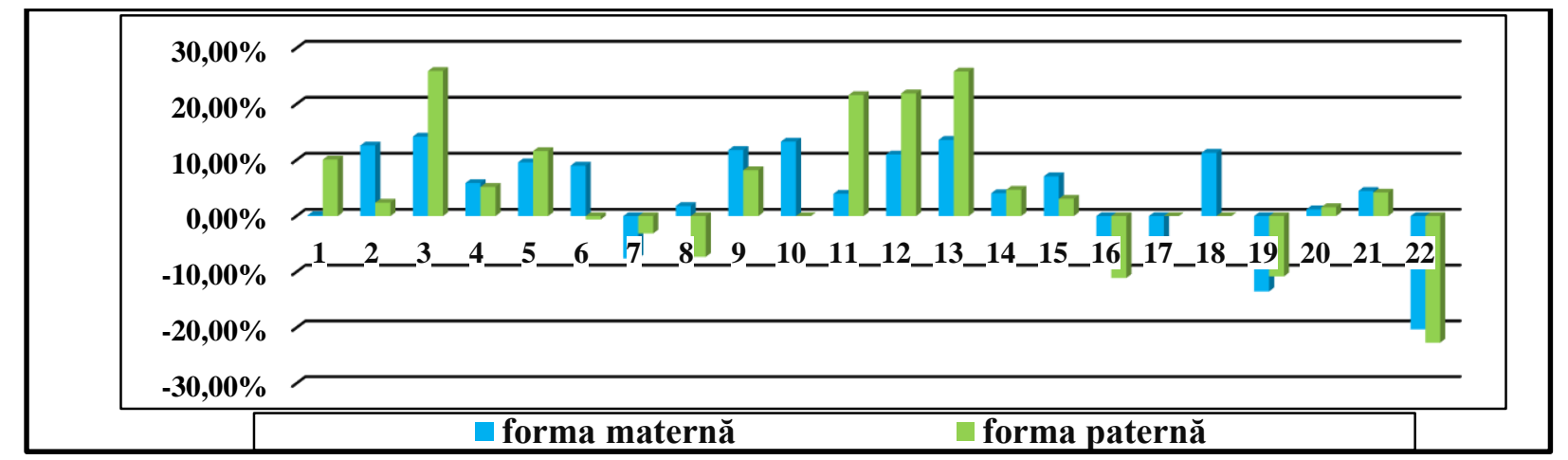

Figura 1. Efectul heterozis manifestat de hibrizii $\mathrm{F}_{1}$ de Salvia sclarea L. la caracterul "talia plantei"

Alt caracter, de care în mare măsură depinde randamentul hibridului, este lungimea inflorescenței. Majoritatea hibrizilor evaluați formează inflorescențe mai mari decât la formele parentale. Lungimea inflorescenței la formele hibride studiate variază între 51.2 și $69.6 \mathrm{~cm}$, iar efectul heterosis este de la +1.5 până la +28.4 \% (fig. 2). Hibrizii simpli (AP 10-11 $\mathrm{S}_{3}$ x AP 34-11 $\left.\mathrm{S}_{3}\right) \mathrm{F}_{1}$, (AP 10-11 $\mathrm{S}_{3}$ x AP 114-11 $\mathrm{S}_{3}$ ) $\mathrm{F}_{1}$, (NC 61-11 $\mathrm{S}_{3}$ x AP 30-11 $\left.\mathrm{S}_{3}\right) \mathrm{F}_{1}$, (NC 6-11 $\mathrm{S}_{3}$ x AP 35-11 $\left.\mathrm{S}_{3}\right) \mathrm{F}_{1}$ și (AP 113-11 $\mathrm{S}_{3}$ x AP 52-11 $\left.\mathrm{S}_{3}\right) \mathrm{F}_{1}$, precum și hibridul în trepte (S. sc.German x Ambriela) $F_{1}$, manifestă heterozis la acest caracter în raport cu ambele forme parentale (fig. 2. nr 1, 3, 11, 9, 5, 21). Cel mai înalt efect al heterozisului la caracterul "lungimea inflorescenței" a fost înregistrat de doi hibrizi simpli: (NC 11-11 $\mathrm{S}_{3}$ x NC 6-11 $\left.\mathrm{S}_{3}\right) \mathrm{F}_{1}$ efectul heterozis $+4.8 \%$ în raport cu forma maternă și $+28.4 \%$ în raport cu forma paternă; (NC 61-11 S 3 x AP 34-11 $\left.\mathrm{S}_{3}\right) \mathrm{F}_{1}$ efect al heterozisului manifestat în raport cu forma maternă fiind de $+16.0 \%$, iar cu forma paternă $+25.1 \%$ și hibridul în trepte (Nataly Clary x Parfum Perfect) $\mathrm{F}_{1}$ a înregistrat $+18.6 \%$ în raport cu forma maternă, iar în raport cu forma paternă $+20.0 \%$ (fig. 2. nr 10, 13, 20)

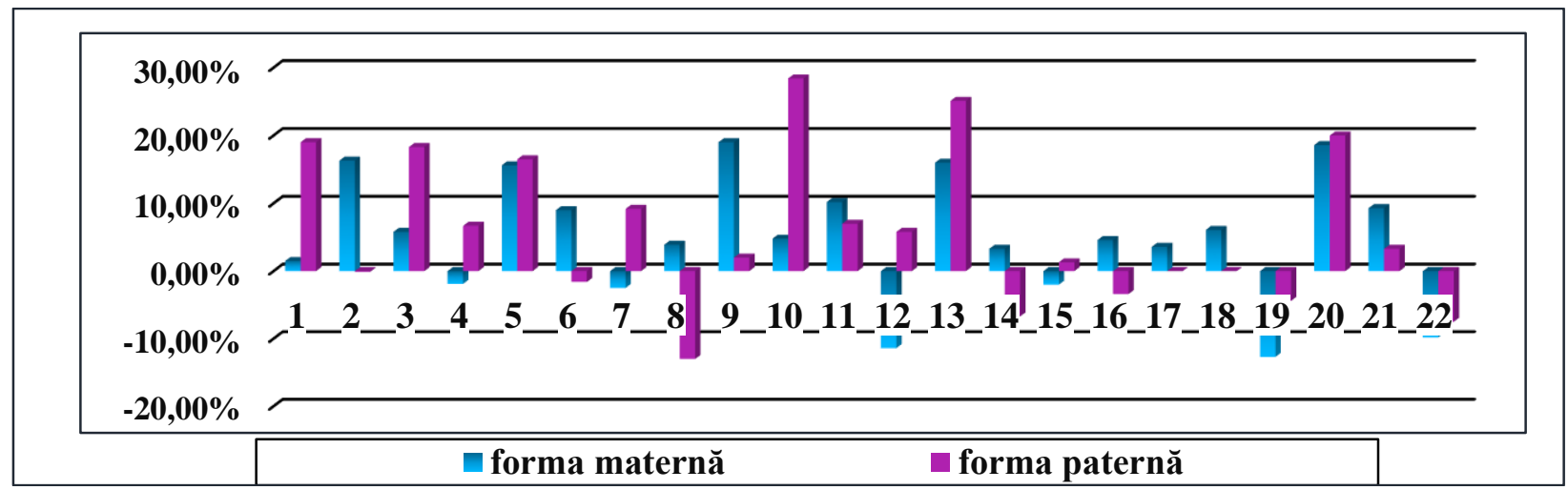

Figura 2. Efectul heterozis manifestat de hibrizii $\mathrm{F}_{1}$ de Salvia sclarea L. la caracterul "lungimea inflorescenței"

Hibrizii $F_{1}$ evaluați, formează inlforescenţe compacte cu număr mare de ramificaţii de gradul întâi şi doi. Atât numărul de verticile, respectiv, flori, cât şi ramificaţiile inlforescenţei influenţează direct conţinutul de ulei esenţial, deoarece glandele oleifere la Salvia sclarea sunt exogene, amplasate pe epidermul ramificaţiilor inlforescenţei şi a sepalelor concrescute ale florilor.

La caracterul „,numărul de ramificaţii” de gradul întâi, efectul heterozis în raport cu ambele forme parentale, cu valori considerabile $(+3.5-+33.3 \%)$, a fost semnalat la șase combinații hibride. Trei hibrizi

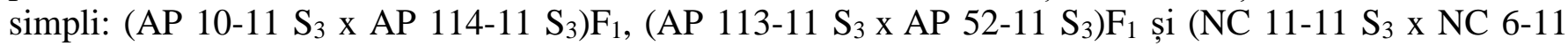


$\left.\mathrm{S}_{3}\right) \mathrm{F}_{1}$, precum şi trei - în trepte și complecși (Basarabia x Ambriela)F $\mathrm{F}_{1}$, (S.sc. German x Ambriela) $\mathrm{F}_{1}$ și (Nataly Clary x Parfum Perfect)F $F_{1}$ (fig. 3. nr. 3, 5, 10, 22, 21, 20).

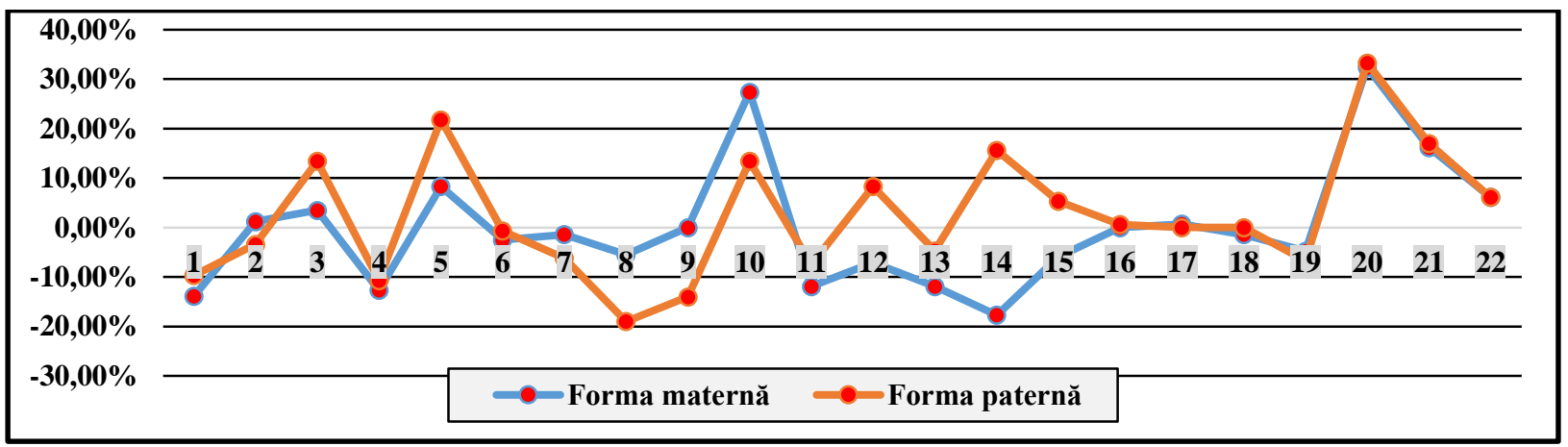

Figura 3. Efectul heterozis manifestat de hibrizii $\mathrm{F}_{1}$ de Salvia sclarea la numărul de ramificaţii de gradul întâi ale inflorescenței

Pentru caracterul "numărul de ramificații" de gradul doi, patru hibrizi $\mathrm{F}_{1}$ : (NC 19-11 S 3 x AP 113$\left.11 \mathrm{~S}_{3}\right) \mathrm{F}_{1}$, (AP 34-11 $\mathrm{S}_{3}$ x AP 10-11 $\mathrm{S}_{3}$ ) $\mathrm{F}_{1}$, (Nataly Clary x S. sc. German) $F_{1}$, (NC 11-11 $\mathrm{S}_{3}$ x NC 6-11 $\left.\mathrm{S}_{3}\right) \mathrm{F}_{1}$, formează inflorescenţe mai compacte de cât la forma paternă, cu număr mai mare de ramificaţii de gradul doi (fig. 4. nr. 12, 2, 19, 10). Cel mai înalt efect al heterozisului în raport cu forma paternă (+73.7\%), a înregistrat hibridul simplu (Cr.p. $99 \mathrm{~S}_{13}$ x AP 52-11 S $\mathrm{S}_{3} \mathrm{~F}_{1}$ (fig. 4. nr. 14).

$\mathrm{Au}$ depăşit ambele forme parentale hibrizii simpli (AP 10-11 $\mathrm{S}_{3}$ x AP 114-11 $\mathrm{S}_{3}$ ) $\mathrm{F}_{1}$ şi (AP 113-11 $\mathrm{S}_{3} \times$ AP 52-11 $\left.\mathrm{S}_{3}\right) \mathrm{F}_{1}$, precum şi hibrizii în trepte și complecşi (S. sc. German x Ambriela) $\mathrm{F}_{1}$, (Basarabia x Ambriela) $F_{1}$ (figura 4, nr. 3, 5, 21, 22). Cel mai înalt efect al heterozisului a fost înregistrat de hibridul în trepte (Nataly Clary x Parfum Perfect) $\mathrm{F}_{1}:+55.8 \%$ în raport cu forma maternă, și $+61.4 \%$ - cu forma paternă (fig. 4, nr. 20).

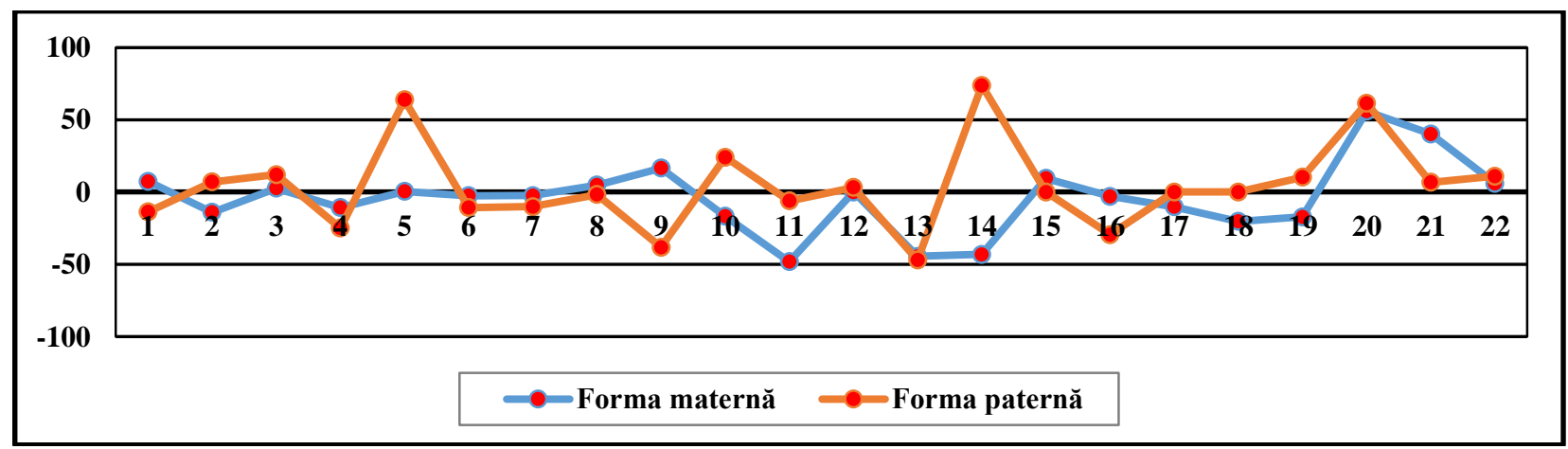

Figura 4. Efectul heterosis la hibrizi $\mathrm{F}_{1}$ de Salvia sclarea pentru ramificaţii de gradul doi ale inflorescenţei.

Inflorescenţele compacte, cu număr mare de ramificaţii de gradul întâi şi doi, număr mare de verticile şi flori contribuie la sinteza şi acumularea uleiului esenţial în concentraţii mai ridicate. Astfel, la unii din hibrizii creaţi conţinutul de ulei esenţial variază de la 0.877 până la $1.836 \%$ (s.u.). Manifestă heterozis în raport cu ambele forme parentale 12 combinații hibride. Efectul heterozis variază de la +7.2 până la $+87.9 \%$ la diferiţi hibrizi (figura 5, nr.1, 2, 3, 4, 5, 6, 7, 8, 10, 12, 13, 16).

Valori ridicate ale heterozisului înregistrează cinci combinații hibride:

1. (AP 10-11 $\mathrm{S}_{3} \times$ AP $\left.114-11 \mathrm{~S}_{3}\right) \mathrm{F}_{1}$, cu conţinutul de ulei esenţial de $0,950 \%$ (s.u.) şi efectul heterozis fiind de $+23,0 \%$ în raport cu forma maternă și respectiv $+41,4 \%$ în raport cu forma paternă (fig. 5. nr. 3);

2. (AP 115-11 $\mathrm{S}_{3} \times \mathrm{NC}$ 60-11 $\left.\mathrm{S}_{3}\right) \mathrm{F}_{1}$, conținutul de ulei esențial - 1,204\% (s.u.), efectul heterozis $+50,3 \%$ în raport cu forma maternă şi $+70,0 \%$ în raport cu forma paternă (fig. 5. nr. 7);

3. (AP 113-11 $\left.\mathrm{S}_{3} \times \mathrm{NC} 19-11 \mathrm{~S}_{3}\right) \mathrm{F}_{1}$, la care conţinutul de ulei esenţial este de $1,683 \%$ (s.u.), efectul heterozis manifestat în raport cu forma maternă $-+72,3 \%$, iar cu forma paternă $-+14,6 \%$ (fig. 5. nr. 8);

4. (NC 19-11 $\mathrm{S}_{3} \times$ AP 113-11 $\left.\mathrm{S}_{3}\right) \mathrm{F}_{1}$ cu ce mai înalt conţinut de ulei esenţial de $\mathbf{1 , 8 3 6 \%}$ (s.u.), efectul heterozis - $+25,0 \%$ în raport cu forma maternă și $+87,9 \%$ - cu forma paternă (fig. 5. nr. 12); 
5. (NC 61-11 $\mathrm{S}_{3} \times$ AP 34-11 $\left.\mathrm{S}_{3}\right) \mathrm{F}_{1}$ - conținutul de ulei esențial constituie 1,110\%(s.u.), efectul heterozis manifestat în raport cu forma maternă fiind de $+46,6 \%$, iar cu forma paternă - +29,8\%, (fig. 5. nr. 13). $\mathrm{S}$-a evidențiat hibridul complecs (Basarabia x Victor) $\mathrm{F}_{1}$, cu conținut de ulei esențial de 1.781\% s.u., efectul heterozisului înregistrat în raport cu forma maternă constituind +80,3\% (fig. 5. nr. 17).

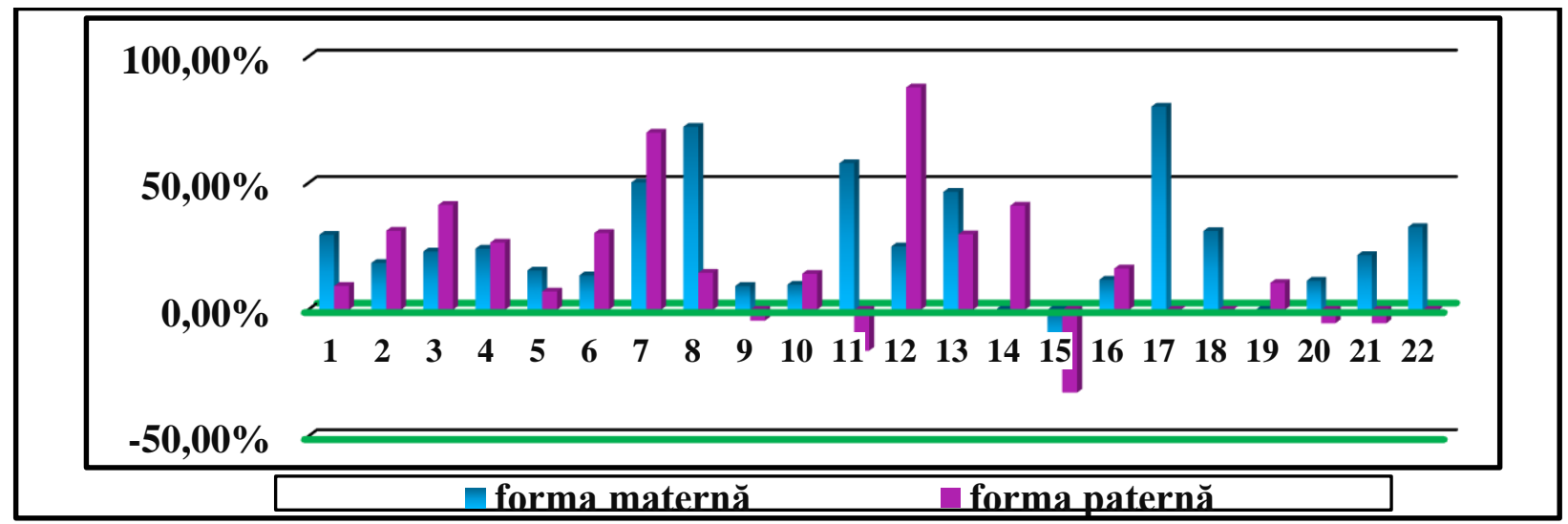

Figura 5. Efectul heterozis la conţinutul de ulei esenţial al hibrizilor F1 de Salvia sclarea L.

\section{Concluzii}

1. Au fost evaluaţi 22 hibrizi $\mathrm{F}_{1}$ de Salvia sclarea L., ce manifestă heterozis la un şir de caractere cantitative, care influenţează direct productivitatea, concomitent fiind un valoros material de ameliorare pentru elaborarea soiurilor noi de provenienţă hibridă.

2. Au manifestat efect remarcabil al heterozisului la numărul de ramificaţii ale inflorescenţei un hibrid în trepte: $+55.8 \%$ în raport cu forma maternă şi $+61.4 \%$ în raport cu forma paternă și $73.7 \%$, heterozis înregistrat de unul din hibrizii simpli în raport cu forma paternă.

3. Conţinutul de ulei esenţial este ridicat $(0.877-1.836 \%)$ cel mai înalt efect al heterozisului fiind înregistrat de un hibrid în trepte: $+25.0 \%$ în raport cu forma maternă, $+87.9 \%$ în raport cu forma paternă şi un hibrid complex: $+80.3 \%$ în raport cu forma paternă.

Cercetările au fost realizate în cadrul proiectului Programului de Stat 20.80009.5107.07 "Diminuarea consecinţelor schimbărilor climatice prin crearea, implementarea soiurilor de plante medicinale şi aromatice cu productivitate înaltă, rezistente la secetă, iernare, boli, ce asigură dezvoltare sustenabilă a agriculturii, garantează produse de calitate superioară, predestinate industriei de parfumerie, cosmetică, farmaceutică, alimentară”, finanțat de Agenția Națională pentru Cercetare și Dezvoltare.

\section{Bibliografie}

1. COTELEA, L., GONCEARIUC, M., BALMUŞ, Z., BUTNARAŞ, V., BOTNARENCO, P. Evaluarea şi selectarea hibrizilor de Salvia sclarea L. în calitate de forme parentale, utilizate în hibridări. În: Ştiinţa în Nordul Republicii Moldova: realizări, probleme, perspective: materialele conf. naţ. cu participare intern., Bălţi, 21-22 iunie 2019. Ed. a 3-a. Bălţi: S. n., 2019 Tipogr. ’Indigou Color", pp. 113-119. ISBN 978-9975-3316-1-6.

2. COTELEA, L. Efectul heterozis la hibrizi $\mathrm{F}_{1}$ în trepte și complecşi de Salvia sclarea L. În: Biotehnologii avansate - realizări şi perspective: al 5-lea simpoz. naţ. cu participare intern., 21-22 oct. 2019: teze. Chişinău, 2019, p. 151. ISBN 978-9975-56-695-7.

3. GONCEARIUC, M. Şerlaiul. În: Ameliorarea specială a plantelor. Chişinău, 2004, p. 525-541.

4. GONCEARIUC, M., COTELEA, L., BALMUŞ, Z., GILLE, E., GITA, G., SPAC, A. Heterozisul înregistrat la hibrizii $\mathrm{F}_{1}$ de Salvia sclarea L. Buletinul Academiei de Ştiinţe a Moldovei. Ştiinţele vieţii, Nr.1(310), 2010, p. 44 -53. ISSN 1857- 064X.

5. ДОСПЕХОВ, Б.А. Методика полевого опыта. Москва. Агропромиздат. 1985. с. 185-245.

6. SHULL, G. Beginnings of the heterosis concept. In: J. Heterosis. SUA: Iowa State College Press, 1952, p. 1448. 